\title{
A CONSULTORIA PARA UM LIVRO EM MULTIFORMATO NO CONTEXTO EDUCACIONAL
}

\section{THE CONSULTANCY FOR A MULTIFORMAT BOOK IN THE EDUCATIONAL CONTEXT}

\author{
Felipe Vieira Monteiro ${ }^{100}$ \\ Edicléa Mascarenhas Fernandes ${ }^{101}$
}

\section{Resumo}

A inclusão no contexto escolar é cada vez mais necessária e pertinente. Escolas e professores vêm se aprimorando para que a equidade na comunicação aconteça de forma plena. Entretanto, o aluno muitas vezes se depara na escola com livros didáticos que foram pensados somente para uma parte do público. Portanto, este artigo tem como objetivo abordar a importância e como é o acesso aos livros didáticos acessíveis em multiformato, detalhando os formatos possíveis, a especificidade de cada um e a quem se destina; e a relevância da consultoria na elaboração deste material utilizado diariamente como recurso pedagógico. Por fim, será realizado um relato da experiência entre o autor de um livro infantojuvenil e o consultor especialista na contribuição para um projeto acessível.

Palavras-chave: Educação inclusiva. Livro didático acessível em multiformato. Recurso de acessibilidade para pessoas com deficiência

\begin{abstract}
Inclusion in the school context is increasingly necessary and relevant. Schools and teachers have been improving themselves so that the equity in communication happens in full. However, students often come across textbooks at school that were designed for only a part of the public. Therefore, this article aims to address the importance and how is access to textbooks accessible in multiformat, detailing the possible formats, the specificity of each one and to whom it is intended; and the relevance of consulting in the preparation of this material used daily as a pedagogical resource. Finally, a report will be made of the experience between the author of a children's book and the specialist consultant in contributing to an accessible project.
\end{abstract}

Keywords: Inclusive education. Multiformat accessible textbook. Accessibility feature for people with disabilities.

\footnotetext{
100 Mestrando em Educação, Cultura e Comunicação em Periferias Urbanas pela UERJ. E-mail: consultorfelipemonteiro@gmail.com. Telefone: (24) 999549874. ORCID: https://orcid.org/0000-0001-88149245.

$\frac{101}{101}$ Professora Associada da UERJ. Programa de Pós-Graduação em Educação, Cultura e Comunicação em Periferias Urbanas FEBF/UERJ. Programa de Pós-Graduação em Ciências, Tecnologia e Inclusão/UFF. E-mail: professoraediclea.uerj@gmail.com. Telefone: (21) 999978397. ORCID: http://orcid.org/0000-0003-3998-2016. 


\section{RevistAleph}

\section{Introdução}

No contexto educacional, é de fundamental importância a relação entre professor e aluno. Neste sentido, Kupfer et al. (2017) afirmam que este laço é a base para um projeto inclusivo. Os autores (2017) citam que a construção da subjetividade é formada por meio das relações em que o professor é colocado como ponto de ancoragem para o educando aprender e, a partir daí, constituir sua subjetividade. Entretanto, alertam para o fato de que o professor não pode e não deve ficar sozinho nesta tarefa, porque é necessário um entendimento de que a escola está inserida no processo.

Desta forma, para que o processo de inclusão ocorra, é necessário um olhar individualizado dentro do coletivo, ou seja, escola e professor devem lançar mão de recursos que atendam à singularidade de cada aluno. Por isso, o livro multiformato é fundamental, pois tem como proposta a difusão da informação para diversos públicos.

Neste artigo, abordaremos a importância dos livros acessíveis, principalmente no contexto educacional, e como é o processo de consultoria dentro da escola, voltado para a eficácia de um produto que atenda às peculiaridades individuais, passando pelo entendimento dos formatos possíveis, especificação de cada um deles e a quem se destina.

Também será realizado um relato do processo de elaboração de um livro multiformato: quais as etapas do processo e os obstáculos e a relação entre a autora da obra e o consultor especialista. Por fim, conclui-se que quanto maior a variedade de formatos de uma mesma obra literária, mais chances de efetivação do processo de inclusão escolar.

\section{A importância e o acesso a livros acessíveis}

Os livros impressos em tinta, com texto verbal, são de conhecimento de todos. Entretanto, será que esse formato é suficiente para satisfazer às particularidades de todos os públicos? Na direção desta reflexão, entende-se a importância dos livros em diversos formatos para atender a essas necessidades. A partir deste fato, a relevância de pensarmos em livros acessíveis principalmente no contexto escolar.

Segundo Souza (2018), os livros multiformatos são caracterizados por oferecerem várias possibilidades de acesso. Em contrapartida, quando se pensa em leitura, nesta 


\section{RevistAleph}

perspectiva, geralmente se tem textos em Braille e raramente textos com leitura fácil, segundo o site Mais Diferenças. Apesar de serem tecnologia assistiva, ainda limitam aqueles que não conseguem utilizar estes tipos de recursos. Como exemplo, o site cita que os surdos, em sua maioria, utilizam a língua portuguesa como sua segunda língua, tendo a Língua Brasileira de Sinais (LIBRAS) como língua principal. Este público tem muita dificuldade de encontrar obras literárias neste formato.

O projeto Diversos: Livros Acessíveis e Inclusivos, citado pelo site Mais Diferenças, tem o propósito de produzir títulos da literatura infantil e infantojuvenil em múltiplos formatos com o intuito de que todas as pessoas tenham acesso às histórias. Ressalta que cada obra reúne diversos recursos que podem ser usados por pessoas com ou sem deficiência. 0 site lista os recursos disponíveis: narração e texto em português, audiodescrição, tradução e interpretação em LIBRAS e leitura fácil. Reforça que os livros ainda contam com animações e trilhas sonoras desenvolvidas especialmente com o objetivo de serem inseridas nas obras acessíveis. Conclui com a informação de que as obras podem ser acessadas gratuitamente pelo site, respeitando os marcos legais relativos aos direitos autorais e aos direitos das pessoas com deficiência.

A leitura é um ato essencialmente cognitivo, segundo Souza (2018), com isso a percepção da tarefa de ler e seus objetivos é determinante para a compreensão operacional e eficaz em relação às outras competências. Souza (2018) lembra que ler é descodificar, com extração do significado da escrita, fazendo com que a leitura seja encarada como um processo de interação entre leitor e texto, criando ressignificação entre eles.

Em relação às crianças, Souza (2018) reforça que a leitura ajuda na criação da identidade e da sua relação com o mundo, tornando-as assim um ser tolerante e ativo. Cita que, a partir do apelo imaginário, a leitura permite transposição de universos, vivência de outros modos de ser, a resolução de conflitos interiores e de problemas de ordem psicossocial. Conclui que é um fator decisivo na maturidade da criança e do adolescente para o equilíbrio afetivo e para a inserção no coletivo da escola e da comunidade em geral. Nesta perspectiva da importância do papel do livro no processo de construção de saberes, torna-se necessário refletirmos sobre a maneira como os diversos públicos terão acesso a este material didático no ambiente educacional. 


\section{RevistAleph}

Em relação a isso, podemos citar a Declaração Mundial sobre Educação para Todos que ocorreu de 5 a 9 de março de 1990 em Jomtien na Tailândia. A declaração baseia-se na consciência de que a educação pode contribuir para a conquista de um mundo mais sadio, seguro, próspero e ambientalmente mais puro, favorecendo o progresso social, cultural e econômico, a tolerância e a cooperação internacional. Mesmo com a certeza de que a educação não é condição eficiente, é de importância fundamental para o progresso social e pessoal. E para a promoção do desenvolvimento, é necessária a constatação de que o conhecimento tradicional e o patrimônio cultural têm valor e utilidade próprios.

Para fomentar e atualizar esta discussão, a Lei Brasileira de Inclusão (LBI), conhecida como Estatuto da pessoa com deficiência, de 6 de julho de 2015, em seu art. 68, Capítulo II, aborda questões do acesso à informação e à comunicação:

Art. 68. O poder público deve adotar mecanismos de incentivo à produção, à edição, à difusão, à distribuição e à comercialização de livros em formatos acessíveis, inclusive em publicações da administração pública ou financiadas com recursos públicos, com vistas a garantir à pessoa com deficiência o direito de acesso à leitura, à informação e à comunicação.

$\S 1$ 을 Nos editais de compras de livros, inclusive para o abastecimento ou a atualização de acervos de bibliotecas em todos os níveis e modalidades de educação e de bibliotecas públicas, o poder público deverá adotar cláusulas de impedimento à participação de editoras que não ofertem sua produção também em formatos acessíveis.

$\S 2$ ㅇ Consideram-se formatos acessíveis os arquivos digitais que possam ser reconhecidos e acessados por softwares leitores de telas ou outras tecnologias assistivas que vierem a substituí-los, permitindo leitura com voz sintetizada, ampliação de caracteres, diferentes contrastes e impressão em Braille. (BRASIL, 2015)

Para reforçar e promover o acesso às obras literárias, em 27 de junho de 2013 foi firmado o Tratado de Marraqueche, que é um tratado internacional assinado em uma conferência em Marrocos por diversos países, como Brasil, Paraguai, Argentina, México, Equador, entre outros. Nesta conferência, 51 países assinaram o tratado, mas atualmente conta com 79 parceiros. Além da assinatura, é necessário que os países ratifiquem o documento.

O objetivo deste acordo é facilitar, através de versões acessíveis, a importação de livros originalmente protegidos por leis de propriedade intelectual. O público-alvo que se beneficia do Tratado de Marraqueche é o de pessoas com deficiência visual, entretanto 


\section{RevistAleph}

sabemos que pode ser útil para todas as pessoas que têm dificuldade de acesso aos textos impressos.

O Brasil promulgou o tratado através do Decreto № 9.522, de 8 de outubro de 2018, com base nos princípios da não discriminação, da igualdade de oportunidades, da acessibilidade e da participação plena e efetiva na sociedade em que foram mencionadas na Declaração Mundial dos Direitos Humanos e na Convenção das Nações Unidas sobre os direitos das pessoas com deficiência.

Na seção seguinte, veremos de que forma as obras acessíveis podem ser apresentadas, ou seja, quais formatos e quais as especificidades de cada uma delas.

\section{Os formatos para os livros acessíveis}

Como vimos na seção anterior, a legislação brasileira nos traz o respaldo no intuito de fomentar e facilitar o acesso às obras literárias inclusivas. Entretanto, é preciso entender de que forma elas podem ser apresentadas e para quais públicos cada formato pode ser direcionado preferencialmente. Antes deste detalhamento, é necessária a compreensão do conceito de tecnologia assistiva.

Segundo o site do Ministério da Ciência, Tecnologia, Inovações e Comunicações do governo brasileiro, a tecnologia assistiva compreende a pesquisa e o desenvolvimento de instrumentos que ampliam a autonomia de pessoas com deficiência ou mobilidade reduzida em suas atividades de vida diária. Essa área do conhecimento engloba produtos, recursos, metodologias, estratégias práticas e serviços que visam promover a independência, qualidade de vida e a inclusão social desses grupos.

Dentro deste escopo, podemos listar alguns formatos que podem ser utilizados para uma obra literária acessível:

1. Braille: É um sistema de escrita e leitura tátil voltado principalmente para as pessoas cegas, mas pode beneficiar as pessoas com baixa visão, segundo o site do Instituto Benjamin Constant (2018). O sistema foi inventado pelo francês Louis Braille que ficou cego aos três anos após um acidente. No site, há a explicação de como o sistema é constituído: arranjo de seis pontos em relevo dispostos na vertical em duas colunas, denominado cela Braille. Conclui que a diferente disposição desses seis pontos permite a formação de 63 


\section{RevistAleph}

combinações ou símbolos para escrever textos, anotações científicas, partituras musicais, além de escrita estenográfica.

2. Fonte ampliada e alto contraste: São recursos voltados prioritariamente para as pessoas com deficiência visual, baixa visão, cujo indivíduo tenha entre 0,3 e 0,05 no melhor olho, isto é, sua perda visual não pode ser corrigida com a utilização de óculos convencionais, segundo Brasil (2004) e Ministério da Educação. Entretanto, todas as pessoas que tiverem algum tipo de limitação visual podem beneficiar-se deste formato. A fonte ampliada deve ser entre 16 e 32, tipo de fonte Arial ou Verdana, que são letras sem serifa ${ }^{102}$. $O$ alto contraste deve ser preferencialmente em fundo escuro com caracteres claros. Os mais utilizados são fundo preto com caracteres brancos ou amarelos.

3. Livro falado ou audiolivro: O sistema Braille presta à comunidade cega e com baixa visão um serviço importante, mas não abrange a todos que a compõem, principalmente aqueles que têm deficiência visual adventícia tardia, ou seja, tornaram-se pessoas com deficiência visual na idade adulta, segundo o site Educa. A solução mais viável é o livro falado, ou seja, material gravado a partir da leitura de um ledor ${ }^{103}$. O audiolivro tem o mesmo princípio, mas conta com mais recursos, como a interpretação do ledor, efeitos sonoros e trilha sonora.

4. Audiodescrição: É um recurso de acessibilidade comunicacional que traduz informações visuais em verbais, fazendo com que principalmente pessoas com deficiência visual tenham acesso às informações de imagens, tabelas, charges, cartuns, desenhos, fluxogramas, entre outros, em obras literárias. Este recurso pode ser disponibilizado através de áudio no formato audiolivro ou livro falado, em fonte ampliada com alto contraste e também em Braille.

5. Videolibras: A LIBRAS é uma língua voltada prioritariamente para os surdos, segundo Cristiano (2017). É a segunda língua oficial brasileira desde 24 de abril de 2002, a partir da Lei $n$ ㅇ 10.436. A LIBRAS é uma língua de sinais ou gestual que utiliza gestos e sinais na substituição da língua de sons ou oral. Este formato é apresentado através de vídeo e pode ter como chave de acesso o QR Code (Quick Response Code - Código de respostas rápidas) que é um sistema em código $2 d$ que originalmente foi criado para rastrear veículos no

\footnotetext{
102 São pequenos traços e prolongamentos que ocorrem no fim das hastes das letras.

103 Pessoa que lê ou grava a leitura para pessoas com deficiência visual. Geralmente são voluntários.
} 


\section{RevistAleph}

processo de fabricação, mas atualmente tem sido utilizado com grande frequência para dar acesso rápido a sites, textos e números. Encontram-se disponíveis, gratuitamente, aplicativos que fazem a leitura destes códigos e também possibilitam a criação e edição destes de forma que podem ser impressos ou apresentados em forma de etiquetas nas obras literárias.

6. Linguagem simples: Formato voltado prioritariamente para as pessoas com Síndrome de Down e outras deficiências intelectuais. São adaptações do texto original de maneira que todas as pessoas, inclusive as que tenham deficiência intelectual, possam compreender o conteúdo disponibilizado, segundo o site Movimento Down. Reforça que as adequações devem ser feitas tanto na forma quanto no conteúdo da mensagem, utilizando palavras mais simples e sentenças mais curtas, apresentando uma ideia de cada vez. Lembra que a fonte deve ser simples sobre fundo liso e em caixa alta. Conclui que as imagens são um grande aliado para essa compreensão.

7. Pictogramas: Segundo o site Pictobike, os pictogramas são representações de objetos e conceitos que são apresentados através da forma gráfica simplificada sem a perda do significado essencial. Lembra que seu uso está geralmente associado à sinalização pública, às instruções e às orientações. Conclui que o uso de pictogramas deve representar conceitos e objetos sem o auxílio de textos, fazendo com que o usuário entenda e identifique de forma fácil.

8. Recursos táteis: São representações táteis de personagens, ambientes, figurinos e quaisquer elementos que contribuam para a melhor percepção das pessoas com deficiência visual. É necessário que esses recursos tenham diferentes texturas para a diferenciação das partes daquele elemento através da percepção háptica. Segundo Brendler et al. (2014), para o desenvolvimento de recursos didáticos táteis é necessário identificar as necessidades do usuário, valorizando a sua bagagem e as especificidades do projeto. O material utilizado deve ser resistente, leve e de fácil manuseio. Os autores (BRENDLER et al., 2014) sugerem que sejam aplicadas etiquetas em Braille se houver necessidade. Concluem com a informação de que, na necessidade de representação de volume, é aconselhável a utilização de uma impressão em 3D.

Os formatos de apresentação de uma mesma obra literária são diversos. Todas as adequações supracitadas já foram aplicadas e demonstraram sua eficácia no contexto escolar, principalmente para as pessoas com deficiência. Portanto, é real a importância da 


\section{RevistAleph}

participação deste público no processo de elaboração e validação do produto que será apresentado, pois, segundo Monteiro (2018), as pessoas com deficiência são a maior autoridade para dizer se um produto ou um trabalho está de acordo com as suas especificidades. Nesta direção, torna-se necessária a participação de um profissional que atue na área como consultor para qualificar o produto que será apresentado.

Na seção seguinte, veremos o perfil do consultor, como ele desenvolve o seu trabalho e os benefícios que a consultoria traz para uma obra literária inclusiva dentro da escola.

\section{A consultoria no processo de elaboração de um livro multiformato dentro da escola}

A variedade de formatos listados na seção anterior demonstra a gama de possibilidades que uma obra literária pode vir a ter para facilitar o acesso, principalmente de pessoas com deficiência. Portanto, a consultoria de um profissional da área é de suma importância para a validação do produto que conta com recursos de tecnologia assistiva, corroborando com a tônica de Sassaki (2011), "Nada sobre nós, sem nós".

Conforme o autor (2011), o "nada" significa a falta de resultados, lei, política pública, programa, serviço, projeto, campanha, financiamento, edificação, aparelho, equipamento, utensílio, sistema, estratégia, benefício, etc. Lembra que cada um destes resultados encontrase em um ou mais campos de atividades, como educação, trabalho, saúde, reabilitação, transporte, lazer, recreação, esportes, turismo, cultura, artes e religião.

Em relação ao "sobre nós", o autor Sassaki (2011) aponta que se refere às pessoas com deficiência de qualquer etnia, raça, gênero, idade, nacionalidade e naturalidade. Reforça que a deficiência pode ser física, intelectual, visual, auditiva, psicossocial ou múltipla.

O mesmo autor (2011) conclui esta avaliação explicando o "sem nós". Afirma que significa sem a plena participação das pessoas com deficiência, que pode ser individual ou coletiva, mediante qualquer meio de comunicação, devendo ocorrer em qualquer fase do processo de elaboração do produto.

Sassaki (2011) também lista as etapas de elaboração nas quais a consultoria deve estar presente, como a elaboração, o refinamento, o acabamento, a implementação, o monitoramento, a avaliação e o contínuo aperfeiçoamento. Salienta que todo produto, o qual 


\section{RevistAleph}

é relacionado às pessoas com deficiência, obrigatoriamente deve ter a participação delas no processo de elaboração, independente da boa intenção das pessoas sem deficiência dos órgãos públicos, das empresas, das instituições sociais e da sociedade em geral.

Nesta perspectiva, é preciso contar com a análise técnica de um profissional específico de cada área para validar cada um dos formatos voltados para obras literárias. Não basta a pessoa ter uma deficiência, é preciso conhecimento direcionado. Entretanto, no ambiente educacional, muitas vezes o professor não tem condições de obter o auxílio profissional por conta da demanda. Então, é necessário o diálogo estreito com o usuário que se beneficiará com o formato que será disponibilizado.

No caso do Braille, é necessário que seja um profissional que atue como revisor Braille, pois ele terá condições de analisar a qualidade do material apresentado, se a impressão está de acordo com a convenção estipulada do sistema e principalmente se o texto está transcrito de forma correta e com fidelidade ao texto original.

A fonte ampliada e com alto contraste deve ser avaliada por uma pessoa com baixa visão que terá condições de indicar se o tamanho e o tipo da fonte estão corretos e se o contraste está disposto de forma confortável para o maior número de usuários possíveis.

O livro falado ou audiolivro deve ser analisado por um profissional que tenha um ouvido apurado para identificar alguns aspectos, como timbre de voz, clareza na pronúncia das palavras, dicção e entonação. Este profissional deve ter conhecimentos sobre técnicas vocais, respiração e estar em contato com profissionais da área de fonoaudiologia.

Tratando-se da audiodescrição, o profissional consultor deve ter uma relação direta com o roteirista que será o responsável por elaborar o roteiro a partir da obra analisada. Esse processo em parceria demanda várias trocas de opiniões até chegarem a um consenso. Este profissional consultor da área de audiodescrição deve ser necessariamente cego ou ter baixa visão e principalmente ter formação na área para poder fazer suas considerações baseadas nas diretrizes que o recurso propõe.

O videolibras deve ser produzido por profissionais qualificados e que tenham fluência na língua. O consultor deve, necessariamente, ser uma pessoa surda e com qualificação para sugerir modificações e adequações para o recurso chegar de forma mais próxima das especificidades do usuário. 


\section{RevistAleph}

A linguagem simples é voltada para as pessoas com deficiência intelectual, portanto é necessário uma pessoa que possua essa deficiência e que tenha intimidade com o recurso para validar o nível de compreensão. Este profissional terá condições de indicar possíveis dificuldades de entendimento, textos longos que causem fadiga e principalmente o vocabulário utilizado.

Já os pictogramas são voltados principalmente para as pessoas que não se comunicam através do som, ou seja, através da comunicação oral. Neste caso, a parceria de quem traduz o texto escrito para o imagético com o usuário deve ser estreita, pois é a partir dos retornos positivos que haverá a percepção de que o texto em forma de imagens está atingindo seu objetivo.

Por fim, os recursos táteis devem ser elaborados com a constante consultoria do profissional da área durante todo o processo: fase da criação, elaboração e finalização. Este profissional deve ter formação na área, além de ter vivência em transitar por equipamentos culturais que ofereçam recursos táteis como tecnologia assistiva.

$\mathrm{Na}$ próxima seção, relato minha experiência como consultor para um livro multiformato, desde as ideias para a implementação dos recursos, avaliação de como tais recursos seriam disponibilizados, validação dos materiais utilizados na impressão Braille, recursos táteis, até a revisão cognitiva dos roteiros de audiodescrição que referem-se à tradução da informação visual em verbal.

\section{Relato: o processo de elaboração entre autor e consultor}

Como foi citado na seção anterior, são inúmeras as possibilidades que podem acessibilizar uma obra literária. Entretanto, o papel do profissional consultor é primordial para a qualidade e eficácia do recurso que será oferecido. Tenho deficiência visual, sou educador há mais de 28 anos, lecionando dentro e fora da sala de aula, especialista em audiodescrição, especialização em acessibilidade cultural, aperfeiçoamento em audiodescrição na escola e mestrando em Educação, cultura e comunicação em periferias urbanas. Baseado na minha experiência, fui convidado a prestar consultoria no processo de elaboração de recursos de tecnologia assistiva para o livro O Espelho Mágico, da autora Loide Leite Aragão Pinto. 


\section{RevistAleph}

A obra O Espelho Mágico faz parte do repertório de histórias da contadora e passa a ter múltiplos formatos acessíveis. Na trama, há a obrigação de que os candidatos à mão da princesa escondam-se dela. A jovem tem um espelho mágico e protagoniza com um herói que merece a gratidão dos animais. A obra foi produzida em 10 formatos diferentes: livro em tinta, audiolivro, audiolivro com audiodescrição, vídeo em LIBRAS, Braille para impressão, fonte ampliada, livro na extensão TXT, texto simplificado, moldes e fantoches e livro em Imagens. Os formatos, em arquivo digital, estão hospedados no site.

A autora entrou em contato comigo com $50 \%$ do projeto encaminhado. Nesta fase, ela já pode apresentar alguns recursos de acessibilidade que a obra teria. Foi muito importante este contato nesta etapa do desenvolvimento do projeto, pois assim pude sugerir diversos elementos que ela poderia readaptar, retirar e inserir para o melhor acesso da obra literária.

Sobre o Braille, foram analisados material utilizado para a impressão, qualidade dos pontos, disposição e também o texto propriamente dito. Além deste formato, recebi o texto digital na extensão TXT, o qual eu deveria analisar utilizando os leitores de tela. Abri o arquivo no computador e o leitor utilizado foi o $\operatorname{NVDA}^{104}$ e, no celular, o sistema Android com a ferramenta TalkBack ${ }^{105}$.

Todas as imagens da obra, incluindo a capa, foram traduzidas para texto por intermédio do recurso da audiodescrição. Conforme a autora concluía o roteiro da imagem, este era enviado via e-mail para que eu fizesse minhas considerações e discutíssemos a melhor maneira de apresentação. Foram necessárias várias trocas até que chegássemos à conclusão de que o roteiro estava em condições para ser apresentado aos usuários.

Também discutimos a melhor maneira de inserir o roteiro da audiodescrição, se seria antes ou depois do texto da história ou se viria exatamente onde a imagem é apresentada. Decidimos que seria onde a imagem é apresentada, pois assim os usuários que têm acesso ao recurso teriam a mesma experiência que os demais. Além deste recurso ser apresentado em Braille e em fonte ampliada com alto contraste, é apresentado também em áudio no livro falado.

\footnotetext{
104 Mais informações: http://www.acessibilidadelegal.com/33-nvda.php.

105 Mais informações: https://tecnoblog.net/247247/o-que-e-o-talkback/.
} 


\section{RevistAleph}

Nesta fase, os formatos se cruzaram, pois, ao mesmo tempo em que eu analisava a qualidade da leitura do texto, no quesito clareza, dicção, tom de voz e detalhes de informações como número da página, capítulo, etc., também analisava a audiodescrição dentro deste contexto. Como esses recursos digitais são disponibilizados através do site, fiz uma varredura neste para confirmar se estava acessível. Ao perceber problemas para a identificação de algum item ou mesmo o acesso a algum conteúdo, relatava para a autora que imediatamente fazia os ajustes.

Por fim, as análises foram direcionadas em relação aos recursos táteis. A cada elemento que proporcionava o reconhecimento háptico, a autora me apresentava para verificar quesitos como textura dos materiais utilizados, clareza das informações apresentadas através das diferenças entre os materiais e qualidade quanto à resistência, já que para esse tipo de recurso a durabilidade é algo de suma importância. Também chamei a atenção para o contraste entre as cores dos materiais para que as pessoas com baixa visão tivessem uma melhor fruição do recurso.

Este diálogo que foi relatado deve acontecer também dentro da sala de aula entre professor e aluno. Dessa forma, a construção e o recurso vão sendo afinados em parceria. A escola, enquanto instituição, deve envolver-se e apoiar este processo, oferecendo condições para todos os envolvidos, além de contribuir para o processo de difusão dos recursos utilizados, de sua importância e do público que necessita desses recursos. Isso deve ocorrer de forma natural, inclusiva e de maneira alguma excludente ou segregadora.

\section{Considerações finais}

Os recursos de acessibilidade, como os livros didáticos acessíveis em multiformato, são tecnologias assistivas que contribuem para a promoção da equidade comunicacional no contexto escolar, atendendo às especificidades individuais dos alunos dentro do coletivo. Os livros didáticos, em sua grande maioria, são apresentados em formatos voltados exclusivamente para um público, em detrimento de outros. Percebemos que existem várias possibilidades da mesma obra literária ser apresentada em distintos formatos, como o Braille, fonte ampliada, alto contraste, audiodescrição, LIBRAS, linguagem simples, pictogramas, 


\section{RevistAleph}

audiolivro e livros falados, além dos recursos táteis. Também foi possível entender como cada formato se constitui, quais suas especificações e para qual público se destina.

Portanto, é de fundamental importância a relação escola, professor e aluno para o desenvolvimento de um projeto de inclusão plena. A consultoria de uma pessoa que será usuária do material diariamente deve ser valorizada para que todas as partes envolvidas entendam as especificidades e aprimorem cada vez mais o material oferecido.

Este artigo trouxe um relato de experiência que ocorreu entre a autora de uma obra literária acessível em multiformato e um consultor especialista em acessibilidade, apresentando as etapas do processo, materiais utilizados e diálogo entre as partes. Também ressaltou que esta relação deve acontecer dentro da sala de aula entre professor e aluno para a equidade comunicacional, mesmo não havendo a possibilidade de uma consultoria especializada.

Vale ressaltar a relevância de pesquisas mais aprofundadas sobre a temática, promovendo a discussão, reflexão e difusão das possibilidades que direcionam a inclusão dentro do ambiente escolar.

\section{Referências}

ARAGÃO, L.. O espelho mágico. Disponível em: https://loidearagao.wixsite.com/meusite/oespelhomagico. Acesso em: 14 abr. 2020.

BRASIL. Decreto n. 5.296, de 2 de dezembro de 2004. Disponível em: http://www.planalto.gov.br/ccivil_03/_ato2004-2006/2004/decreto/d5296.htm. Acesso em: 18 jan. 2020.

BRASIL. Decreto n. 9.522, de 8 de outubro de 2018. Disponível em: http://www.planalto.gov.br/ccivil_03/_Ato2015-2018/2018/Decreto/D9522.htm. Acesso em: 3 jan. 2020.

BRASIL. Lei n. 13. 146, de 6 de julho de 2015. Disponível em: http://www.planalto.gov.br/ccivil_03/_ato2015-2018/2015/lei/l13146.htm. Acesso em: 30 dez. 2019.

BRENDLER, C. F.; VIARO, F. S.; BRUNO, F. B.; TEIXEIRA, F. G.; SILVA, R. P. da. Recursos didáticos táteis para auxiliar a aprendizagem de deficientes visuais. Educação Gráfica, ano 2014, v. 18, n. 03. Disponível em: https://lume.ufrgs.br/bitstream/handle/10183/148932/000953276. pdf?sequence=1\&isAllowed=y. Acesso em: 23 jan. 2020. 
CRISTIANO, A.. O que é LIBRAS? Publicado em: 17 maio 2017. Disponível em: http://www.libras.com.br/o-que-e-libras. Acesso em: 18 jan. 2020.

DECLARAÇÃO MUNDIAL SOBRE EDUCAÇÃO PARA TODOS. Plano de ação para satisfazer as necessidades básicas de aprendizagem. Nova lorque, abril de 1990. Disponível em: http://www.direitoshumanos.usp.br/index.php/Direito-a-Educa\%C3\%A7\%C3\%A3o/declaracaomundial-sobre-educacao-para-todos.html/. Acesso em: 31 dez. 2019.

EDUCA. Convivendo com a diferença: livro falado: gravando livros para cegos. Disponível em: http://www.oieduca.com.br/artigos/convivendo-com-a-diferenca/livro-falado.html. Acesso em: 18 jan. 2020.

INSTITUTO BENJAMIN CONSTANT. O sistema Braille. Publicado em: 11 maio 2018. Disponível em: http://www.ibc.gov.br/index.php?option=com_content\&view=article\&id=675:0-sistemabraille\&catid=121\&Itemid=373. Acesso em: 18 jan. 2020.

KUPFER, M. C. M.; PATTO, M. H. Souza; VOLTOLINI, R. (Orgs.). Práticas inclusivas em escolas transformadoras: acolhendo o aluno-sujeito. 1 ed. São Paulo: Escuta: Fapesp, 2017. 416 p.

MAIS DIFERENÇAS. Diversos: livros acessíveis e inclusivos. Disponível em: https://maisdiferencas.org.br/projeto/diversos-livros-acessiveis-e-inclusivos/. Acesso em: 10 fev. 2020.

MINISTÉRIO DA CIÊNCIA, TECNOLOGIA, INOVAÇÕES E COMUNICAÇÕES. Tecnologia assistiva. Disponível em:

https://www.mctic.gov.br/mctic/opencms/ciencia/tecnologia_assistiva/_assistiva/Tecnologia_Assist iva.html. Acesso em: 13 jan. 2020.

MINISTÉRIO DA EDUCAÇÃO. Orientações para professores de estudantes com baixa visão. Universidade Federal do Recôncavo da Bahia. Pró-Reitoria de graduação. Núcleo de políticas de inclusão. Disponível em:

https://www1.ufrb.edu.br/nupi/images/documentos/Orientaes\%20para\%20professores\%20de\%20e studantes\%20com\%20baixa\%20viso.pdf. Acesso em: 18 jan. 2020.

MONTEIRO, F. V.. Análise de lexias "tabus" na audiodescrição de imagens estáticas de sexo explícito no filme "A história da eternidade". UECE, 2018. TCC (Especialização em Tradução audiovisual acessível: audiodescrição) - Centro de Humanidades, Universidade Estadual do Ceará, Fortaleza, 2018.

MOVIMENTO DOWN. Comunicação acessível. Disponível em:

http://www.movimentodown.org.br/jovens-e-adultos/o-que-e-comunicacao-acessivel/. Acesso em: 20 jan. 2020.

PICTOBIKE. O que são pictogramas? Disponível em: https://pictobike.wordpress.com/o-que-saopictogramas/. Acesso em: 19 jan. 2020.

SASSAKI, R. K.. Nada sobre nós, sem nós: da integração à inclusão. Publicado em: 22 jun. 2011. Disponível em: http://www.bengalalegal.com/nada-sobre-nos. Acesso em: 21 jan. 2020. 


\section{RevistAleph}

SOUZA, C.. Projeto de leitura inclusiva partilhada. Instituto Politécnico de Leiria, 2018. Disponível em: http://eventos.ccems.pt/inclusao/userfiles/File/Apresentacoes2018/CeliaSousa.pdf. Acesso em: 31 dez. 2019.

Data do envio: $15 / 04 / 2020$

Data do aceite: 04/06/2020. 